\title{
BMJ Open Factors associated with domestic violence: a cross-sectional survey among women in Jeddah, Saudi Arabia
}

To cite: Fageeh WMK. Factors associated with domestic violence: a crosssectional survey among women in Jeddah, Saudi Arabia. BMJ Open 2014;4: e004242. doi:10.1136/ bmjopen-2013-004242

- Prepublication history for this paper is available online. To view these files please visit the journal online (http://dx.doi.org/10.1136/ bmjopen-2013-004242).

Received 20 October 2013 Revised 23 January 2014 Accepted 24 January 2014

CrossMark

Department of Obstetrics and Gynecology, King Abdulaziz University Hospital, Jeddah, Saudi Arabia

Correspondence to Dr Wafa M K Fageeh; fageeh.wafa@gmail.com

\begin{abstract}
Objective: This study aims to identify the factors associated with domestic violence (DV) among women in Jeddah.

Design: Cross-sectional survey.

Setting: Outpatient departments of three tertiary hospitals in Jeddah.
\end{abstract}

Participants: Convenience sample of women, aged 15-70 years, at the outpatient and inpatient clinics.

Interventions: Between 15 December 2011 and 30 May 2012, a psychologist and a professional health assistant explained the purpose of the research to participants, who were then asked to fill a 50-item questionnaire. The questionnaire was created based on questions from three questionnaires: the NorVold Domestic Abuse Questionnaire, the Pregnancy Risk Assessment Monitoring System and the Kansas Marital Satisfaction Scale. The questionnaire was used to assess the association between DV and family status, male partner attitudes, age, educational attainment, employment, financial and socioeconomic status.

Results: A total of 2301 women participated in the survey ( $81 \%$ response rate). The mean $\pm \mathrm{SD}$ age of the participants was $34.4 \pm 10.9$ years. The lifetime prevalence of DV was $34 \%$. Abused women had more children than non-abused women $(p=0.001)$, and their spouses were significantly older than those of non-abused women $(p<0.0001)$. Financially dependent women and those with a high educational status were significantly more likely to report abuse $(p=0.003$ and $p<0.001$, respectively). Abused women were also likely to report that their spouse was a smoker $(p<0.0001)$ and had completed at least primary or secondary education $(p<0.0001)$. A significantly lower proportion of abused women reported that their male partners were alcohol users $(p=0.001)$. The results of logistic regression showed that women who were financially dependent had about 1.5 -fold odds of being physically abused by a spouse.

Conclusions: Many factors are associated with DV against women, thereby highlighting the need to design effective DV prevention programmes.

\section{INTRODUCTION}

Domestic violence (DV) is a common problem that affects men and women

\section{Strengths and limitations of this study}

- The cross-sectional nature of our study prohibits conclusions about causality, predictive ability and labelling variables as risk factors.

- Only women were surveyed, and the data relied solely on the reports of the participants.

- We recruited a convenience sample of women owing to the difficulties in approaching leaders of women's gathering groups, who were hesitant to give their approval because of the relatively sensitive nature of our theme.

- We did not report factors such as gender, race and ethnicity of the psychologist and health assistant who were present during data collection. These factors would have been important to consider when estimating the reliability and validity of our questionnaire.

- Some women did not respond to certain questions for fear of disclosing too much personal information.

- The potential impact on the self-report of women who needed assistance in completing their questionnaires should also be taken into consideration, as sensitive information was obtained.

worldwide. It was a formerly neglected public health problem, which has gained more visibility over the past few decades. Since its recognition as a serious human rights abuse and important public health problem at key international conferences during the 1990s, including the Fourth World Conference on Women, ${ }^{1}$ researchers have shown the increasing prevalence of violence perpetrated on women by their male partners. It was estimated that between $10 \%$ and $52 \%$ of women from 35 countries worldwide reported that they had been physically abused by an intimate partner at some point in their lives, and approximately $10-30 \%$ reported they had experienced sexual violence by an intimate male partner. ${ }^{23}$

In the Middle East, there is a paucity of studies on DV although there is a growing body of evidence highlighting the magnitude 
of this problem among women in developing countries. ${ }^{4}$ Findings from previous studies conducted in Egypt, Israel, Palestine and Tunisia indicate that at least one of three women was a victim of DV. ${ }^{4}$ According to results from two demographic health surveys conducted in Egypt (in 1995 and 2005), with a 10 years gap between them, beating by an intimate partner was highly prevalent despite increasing levels of education and was not limited to selected risk groups. ${ }^{6}$

Until quite recently, DV was a hidden problem in Saudi Arabia. Only few studies have reported the prevalence of DV among women in three different regions of Saudi Arabia, with prevalence rates ranging from 39.3\% to as high as $57.7 \% .^{78}$ This high prevalence is compounded by cultural norms, which prevent women from reporting cases of abuse for fear of social stigma. In their study, Tashkandi and Rasheed ${ }^{7}$ found that $25.7 \%$ of ever-married women attending primary health centres in Medina reported physical abuse; emotional abuse without physical violence was reported in $32.8 \%$ of the cases. Of those physically abused, $36.7 \%$ and $63.3 \%$ suffered minor and severe incidents, respectively. Afifi et $a l^{8}$ in a community based-study conducted in Al-Ahsa oasis in the Eastern Province of Saudi Arabia, found that $29.1 \%$ of the women reported mental abuse, while $22.8 \%$ and $11.8 \%$ reported physical and sexual abuse, respectively. However, none of these studies identified the factors associated with DV, which is an important step towards designing effective DV prevention programmes. This study was designed to identify the factors, such as the woman's educational status, ${ }^{9} 10$ occupation, ${ }^{9}{ }^{11}$ age,${ }^{1012} 13$ socioeconomic status, ${ }^{9}{ }^{14}$ alcohol consumption $^{10-14}$ and number of children, ${ }^{11} 15$ which have been reported to be significantly associated with spousal abuse.

\section{METHODS}

\section{Participants}

A cross-sectional survey was performed between 15 December 2011 and 30 March 2012 at three tertiary hospitals in Jeddah, namely King Abdulaziz University Hospital, King Abdulaziz Oncology Medical Center and King Fahd General Hospital. King Abdulaziz University Hospital was the first university hospital, created in 1956. King Abdulaziz Oncology Medical Center is the largest hospital of the Ministry of Health and King Fahd General Hospital is the largest government hospital that renders medical services in most of the major specialties and subspecialties.

The target population consisted of a convenience sample of ever-married women (patients, caregivers and visitors), aged 15-70 years. Marriages among women younger than 20 years is uncommon in Saudi Arabia, ${ }^{16}$ and abuse among women aged above 50 years has not been explored in previous studies conducted in the country. ${ }^{7} 8$ We excluded all single women and those aged $<15$ or $>70$ years. All participants gave their consent to participate after the nature of the study had been fully explained.

We included 2301 women from the outpatient and inpatient departments of the aforementioned hospitals. Of these, 2072 respondents completed the questionnaire, representing an overall response rate of $90 \%$. Non-responders, including women who provided partial or incomplete information, comprised $10 \%$ of the sample population $(n=229)$. A follow-up study of nonresponders was not performed, as the survey was conducted in a public place.

The purpose of the research was explained by a psychologist and a professional health assistant to all the participants, who were then asked to fill a 50-item questionnaire that comprised questions to identify ever exposure to DV. Special assistance was provided to the illiterate and in cases where further explanation was necessary. The women were requested to fill the questionnaire in a private room that was reserved for this purpose. Participants were guaranteed confidentiality of their responses; they were assured that there would be no specific reference to individuals, but the findings and conclusions will be stated in general terms.

\section{Instrument}

We used a questionnaire that was created based on questions from three questionnaires, namely the NorVold Domestic Abuse Questionnaire, the Pregnancy Risk Assessment Monitoring System (PRAMS) and the Kansas Marital Satisfaction Scale. ${ }^{17} 1819$

\section{Items assessed}

The questionnaire comprised six sections: (1) the personal data of the couple, including their educational attainment, employment status and their annual household incomes; (2) items that covered physical, psychological and sexual abuse; (3) help-seeking options of abused women; (4) the damaging effect of violence on the victims; (5) items to score the level of happiness, extracted from the Kansas Marital Satisfaction Scale ${ }^{18}$ and (6) items to evaluate the effect of violence on pregnancy and its outcome, extracted from the PRAMS. ${ }^{18}$ The questionnaire was translated into Arabic, and it was revised by experts for accuracy, clarity and understanding.

In order to describe the mode of living of the participants, we took into consideration the kind of house they rented or owned. Participants were categorised into four groups: (1) lived in rented apartments, (2) lived in self-owned apartments, (3) lived in rented villas and (4) lived in self-owned villas. The monthly income of the husband was classified into low (1000-3000 SAR/month), middle (>3000-5000 SAR/month) and high ( $>5000 \mathrm{SAR} /$ month).

Physical violence was defined as having ever been pushed, beaten, slapped, kicked, hit with a fist or object, pulled by the hair, dragged, burned or threatened or attacked with a knife or gun by a spouse or family member. Psychological abuse was defined as having ever 
been threatened by a spouse or family member, prevented from visiting or calling family members and friends or insulted. Sexual violence was defined as having ever been forced by a spouse or family member to have unwanted intercourse.

We classified marital satisfaction into extremely dissatisfied, very dissatisfied, somewhat dissatisfied, mixed feelings, somewhat satisfied, very satisfied and extremely satisfied.

\section{Statistical analysis}

Data analysis was performed using the Statistical Package for the Social Sciences (SPSS Inc, Chicago, Illinois, USA), V.18. We used the independent t-test for equal variance and Welch's t test for unequal variance. $\chi^{2}$ Test was used to determine the association between variables. A logistic regression model was used to predict the odds of being abused. $\mathrm{p}<0.05$ was considered statistically significant $(95 \%$ CI $)$.

Cronbach's $\alpha$ was used to test the internal consistency of items that attempted to assess marital satisfaction among women who were physically, sexually or emotionally abused. If Cronbach's $\alpha$ was $>0.70$, then the ratio scale was considered reliable.

\section{RESULTS}

A total of 2301 women participated in the survey, representing a response rate of $81 \%$. Saudi women comprised $58.3 \%$ of the sample $(n=1342)$, while expatriate women made up $41.7 \%$ of the population $(n=959)$. Of the expatriate women, $345(15 \%)$ were Yemenis, $126(5.5 \%)$ Palestinians, 65 (2.8\%) Egyptians, 30 (1.3\%) Somalis, 118 (5.1\%) from African countries and 275 (11.9\%) from neighbouring countries. In total, 1908 women $(82.9 \%)$ were Arabs. Regarding their religious inclinations, 2235 women $(97.1 \%)$ were Muslims, while 23 (1\%) were Christians; 43 women did not specify their religion.

The mean \pm SD age of the women was $34.4 \pm 10.9$ years. Married women constituted $65.9 \%$ of the study population $(\mathrm{n}=1516) ; 607$ women $(26.4 \%)$ were divorced, $58(2.5 \%)$ were widowed, $36(1.6 \%)$ were single; 84 women $(3.8 \%)$ did not disclose their marital status.

The lifetime prevalence of DV in our cohort was 34\%: emotional abuse, 29\%; physical abuse, $11.6 \%$ and sexual abuse, $4.8 \%$. Based on marital status, $67.3 \%$ of the women who reported abuse were married $(n=509) ; 28.4 \%$ of abused women were divorced, $2.9 \%$ were widows $(n=22)$, while $1.3 \%$ were separated $(n=10)$. By $\chi^{2}$ test, we did not find a significant difference between abused and nonabused women based on their nationality ( $p=0.689)$.

In comparing the Saudi versus non-Saudi population, no statistical difference was found in the age distribution between both groups the majority of the participants were aged between 20 and 40 (Non-Saudis $75 \%$ vs. Saudis $72.7 \%)(p=0.465)$. Concerning the marital status, a higher percentage of the non-Saudi group was found to be either separated $(6.1 \%$ vs Saudis $2.2 \%)$, or married (67\% vs Saudis 64\%) ( $\mathrm{p}=0.000)$. The non-Saudi group was also found to have a lower standard of living and lower education ( $74 \%$ rented apartments vs Saudis $39 \%)\left(\mathrm{p}=0.000^{*}\right)$. This was not reflected on the employment status or the financial dependence on the husband, where no statistical difference was found between Saudis (Non-Saudis 79\% unemployed and $72.7 \%$ financially dependent on spouse vs Saudis $76 \%$ unemployed and $72.0 \%$ financially dependent) and non-Saudis $(p=0.067-0.708)$, respectively. With regard to the abuse of women, there was no significant difference between both groups (lifetime prevalence of $\mathrm{DV}$ in Non-Saudis 33.5\% vs Saudis 34.3\%) ( $\mathrm{p}=0.689$ ).

For internal reliability, Cronbach's $\alpha$ coefficient was used to evaluate subscales of the DV against women; it showed that Cronbach's $\alpha$ equals $0.955,0.835$ and 0.888 for physical, emotional and sexual violence, respectively, with a total score of 0.931 .

Further analysis showed that illiterate women and those who had completed primary education and high school were significantly more likely to report abuse (illiterate, primary education and high school $64.6 \%$ vs higher education $35 \%)(p<0.0001$; table 1$)$. Women who were financially dependent on their spouses were also significantly more likely to report abuse $(71.7 \%) \quad(p=0.003)$. Spousal abuse was more frequent in the group of women aged $>50$ years, but this difference did not reach statistical significance.

The spouses of women who reported DV were significantly older than those of non-abused women (43.2 \pm 12.3 vs. $41.2 \pm 11.9) \quad(\mathrm{p}<0.0001$; table 2$)$. Participants who reported DV were likely to report that their spouses had completed at least primary or secondary education (40.9\% illiterate and primary education vs. $30 \%$ high school vs. $27.5 \%$ higher education $)(p<0.0001)$. They were more likely to also report that their male partner was a smoker $(78.5 \%)(\mathrm{p}<0.0001)$. Conversely, a significantly lower proportion of abused women reported that their male partners were alcohol users (40.9\%) $(\mathrm{p}=0.001)$.

The results of logistic regression showed that women who were financially dependent had about 1.5 -fold odds of being physically abused by a spouse. Women whose spouses had completed at least primary education had twice the odds of being abused; the odds were also higher in women who had completed primary education. However, these results did not reach statistical significance.

Abused women were significantly more likely to report body self-hatred, food addiction and hopelessness (table 3). On the contrary, gastrointestinal disorders and loss of trust in others were significantly more frequently reported in the non-abused group.

Gynaecological disorders, including abortions, metrorrhagia and menorrhagia were significantly more reported in the abused group (table 4). Victims of DV were also more likely to report having less weight gain during pregnancy and babies with lower birth weights, but these results did not reach statistical significance. 
Table 1 Characteristics of the abused and non-abused women*

\begin{tabular}{|c|c|c|c|c|}
\hline & Non-abused & Abused & Total† & p Value \\
\hline Number of children & $3.67 \pm 2.38$ & $4.06 \pm 2.59$ & - & 0.001 \\
\hline Clomiphene-treated cycles (n) & $2.63 \pm 4.31$ & $2.51 \pm 3.81$ & - & 0.768 \\
\hline Number of children in the women's families & $7.10 \pm 3.57$ & $7.33 \pm 3.53$ & - & 0.145 \\
\hline \multicolumn{5}{|l|}{ Age (years) $\ddagger$} \\
\hline$<20$ & $44(65.7)$ & $23(34.3)$ & $67(100.0)$ & \multirow[t]{6}{*}{0.829} \\
\hline $21-30$ & $556(67.5)$ & $268(32.5)$ & $824(100.0)$ & \\
\hline $31-40$ & $553(65.6)$ & $290(34.4)$ & $843(100.0)$ & \\
\hline $41-50$ & $320(64.4)$ & $175(35.6)$ & $495(100.0)$ & \\
\hline$>50$ & $25(62.5)$ & $15(37.5)$ & $40(100.0)$ & \\
\hline Total & $1498(66.0)$ & $771(34.0)$ & $2269(100.0)$ & \\
\hline \multicolumn{5}{|l|}{ Mode of living } \\
\hline Rented apartment & $754(64.3)$ & $418(35.7)$ & $1172(100.0)$ & \multirow{5}{*}{0.196} \\
\hline Owned apartment & $545(66.9)$ & $270(33.1)$ & $815(100.0)$ & \\
\hline Rented villa & $61(68.5)$ & $28(31.5)$ & $89(100.0)$ & \\
\hline Owned villa & $112(72.3)$ & $43(27.7)$ & $155(100.0)$ & \\
\hline Total & $1472(66.0)$ & 759 (34.0) & $2231(100.0)$ & \\
\hline \multicolumn{5}{|l|}{ Educational attainment } \\
\hline Illiterate & $118(62.4)$ & $71(37.6)$ & $189(100.0)$ & \multirow[t]{5}{*}{$<0.0001$} \\
\hline Primary & $179(58.9)$ & $125(41.1)$ & $304(100.0)$ & \\
\hline Secondary & $493(65.0)$ & $266(35.0)$ & $759(100.0)$ & \\
\hline College & 629 (71.3) & $253(28.7)$ & $882(100.0)$ & \\
\hline Total & 1419 (66.5) & 715 (33.5) & $2134(100.0)$ & \\
\hline \multicolumn{5}{|l|}{ Employment status } \\
\hline Unemployed & $1072(65.2)$ & $571(34.8)$ & $1643(100.0)$ & \multirow[t]{3}{*}{0.331} \\
\hline Employed & $344(67.6)$ & $165(32.4)$ & 509 (100.0) & \\
\hline Total & $1416(65.8)$ & $736(34.2)$ & $2152(100.0)$ & \\
\hline \multicolumn{5}{|l|}{ Financially dependent } \\
\hline Yes & $1129(67.6)$ & $542(32.4)$ & $1671(100.0)$ & \multirow[t]{3}{*}{0.003} \\
\hline No & $329(60.7)$ & 213 (39.3) & $542(100.0)$ & \\
\hline Total & $1458(65.9)$ & $755(34.1)$ & $2213(100.0)$ & \\
\hline
\end{tabular}

Although a large proportion of women reported being satisfied to extremely satisfied in their marriages, abused women were significantly more likely to report being unsatisfied or extremely unsatisfied in their marriages (table 5).

A small proportion of abused women sought help from their families $(n=72,3.1 \%)$ or their husbands' families $(n=73,3.2 \%)$. Only 56 women $(2.4 \%)$ planned to see a psychiatrist, while $24(1 \%)$ planned to contact social services.

\section{DISCUSSION}

This is the first study to explore the factors associated with DV in a large cohort of women in Jeddah, Saudi Arabia. The characteristics analysed were sociodemographic (age, marital status, educational attainment, employment status, economic autonomy) and behavioural (spousal alcohol, cigarette and drug use). Although expatriate women comprised nearly half of the sample, all the women were subject to the same threat, as there are limited consequences for perpetrators of $\mathrm{DV}$ in a society that is primarily ultraconservative.
This allowed us to combine native Saudi and expatriate women.

The Cronbach's $\alpha$ coefficients reported in this study showed similar values to that published in other studies. An article published in Sweden 2013 showed that the reliability coefficients were 0.79 (psychological scale), 0.80 (physical scale), 0.72 (sexual scale) and 0.88 (total scale). ${ }^{20}$ These findings were in line with ours. This could be interpreted as a similarity in internal reliability in spite of differences in culture and socioeconomic status between more liberal countries such as Sweden and a conservative country such as Saudi Arabia.

Our analysis supports the view that women who are unemployed or financially dependent on their spouses may be more likely to experience DV. In particular, financial dependence was associated with approximately 1.5-fold odds of spousal abuse, after controlling other factors, such as age, educational attainment and the number of children. While economic factors are usually implicated in $\mathrm{DV},{ }^{21}{ }^{22}$ some authors reported that employment status and relative earnings were not predictive of $\mathrm{DV} .^{23}$ According to one report, the ability of a woman to leave her abusive male partner was also 
Table 2 Characteristics of the spouses of abused and non-abused women*

\begin{tabular}{|c|c|c|c|c|}
\hline Characteristic & Non-abused & Abused & Total† & p Value \\
\hline Husband's age (mean $\pm S D$ in years) & $41.2 \pm 11.9$ & $43.2 \pm 12.3$ & - & $<0.0001$ \\
\hline \multicolumn{5}{|l|}{ Husband's educational attainment } \\
\hline Illiterate & $87(53.0)$ & $77(47.0)$ & $164(100.0)$ & \multirow[t]{6}{*}{$<0.0001$} \\
\hline Primary & $339(60.9)$ & $218(39.1)$ & $557(100.0)$ & \\
\hline Secondary & 449 (67.4) & 217 (32.6) & $666(100.0)$ & \\
\hline College & $463(71.0)$ & $189(29.0)$ & $652(100.0)$ & \\
\hline Masters & $31(62.0)$ & $19(38.0)$ & $50(100.0)$ & \\
\hline Total & $1369(65.5)$ & $720(34.5)$ & $2089(100.0)$ & \\
\hline \multicolumn{5}{|c|}{ Husband's average income (in Saudi Arabian Riyals) } \\
\hline $1000-3000$ & $644(66.6)$ & $322(33.4)$ & $966(100.0)$ & \multirow[t]{5}{*}{0.219} \\
\hline$>3000-5000$ & 317 (68.2) & $148(31.8)$ & $465(100.0)$ & \\
\hline$>5000-10000$ & $254(63.7)$ & 135 (36.3) & $399(100.0)$ & \\
\hline$>10000$ & $176(73.3)$ & $64(26.7)$ & $240(100.0)$ & \\
\hline Total & $1401(67.7)$ & 669 (32.3) & $2070(100.0)$ & \\
\hline \multicolumn{5}{|l|}{ Smoker } \\
\hline Yes & 419 (58.3) & $300(41.7)$ & 719 (100.0) & \multirow[t]{3}{*}{$<0.0001$} \\
\hline No & $215(72.4)$ & $82(27.6)$ & $297(100.0)$ & \\
\hline Total & 634 (62.4) & $382(37.6)$ & $1016(100.0)$ & \\
\hline \multicolumn{5}{|l|}{ Consumes alcohol } \\
\hline Yes & $23(47.9)$ & $25(52.1)$ & $48(100.0)$ & \multirow[t]{3}{*}{0.001} \\
\hline No & $104(74.3)$ & $36(25.7)$ & $140(100.0)$ & \\
\hline Total & $127(67.6)$ & $61(32.4)$ & $188(100.0)$ & \\
\hline \multicolumn{5}{|l|}{ Drug user } \\
\hline Yes & $14(70.0)$ & $6(30.0)$ & $20(100.0)$ & \multirow[t]{3}{*}{0.888} \\
\hline No & $505(68.5)$ & $232(31.5)$ & 737 (100.0) & \\
\hline Total & $519(68.5)$ & $238(31.4)$ & $757(100.0)$ & \\
\hline
\end{tabular}

dependent on her economic autonomy. ${ }^{21}$ In societies where a woman can live on her own, a woman may be more inclined to stay with an abusive partner when she does not have the means to afford housing. However, this may not apply to the Saudi society where a woman cannot live on her own and is obliged to live with her relatives if she is single or divorced or with her husband.

Table 3 Binary logistic regression analysis of factors associated with domestic violence

\begin{tabular}{lll}
\hline Variables & OR & p Value \\
\hline Number of children & 1.019 & 0.547 \\
Husband's age & 0.999 & 0.882 \\
Number of abortions & 1.055 & 0.270 \\
Woman's educational attainment & & 0.244 \\
$\quad$ Illiterate & 1.172 & 0.575 \\
$\quad$ Primary education & 1.487 & 0.084 \\
$\quad$ Secondary education & 1.327 & 0.095 \\
$\quad$ Financially dependent on husband & 1.572 & 0.001 \\
Husband's educational attainment & & 0.034 \\
$\quad$ Primary education & 2.102 & 0.146 \\
$\quad$ Secondary education & 1.060 & 0.900 \\
$\quad$ College graduate & 1.136 & 0.781 \\
$\quad$ Master's & 0.825 & 0.674 \\
\hline
\end{tabular}

Table 4 Common mental, medical and gynaecological and obstetrical problems reported by the respondents ${ }^{\star}$

\begin{tabular}{|c|c|c|c|}
\hline & Non-abused & Abused & p Value \\
\hline $\begin{array}{l}\text { Weight gain in } \\
\text { pregnancy }(\mathrm{kg})\end{array}$ & $13.85 \pm 14.96$ & $13.56 \pm 14.86$ & 0.696 \\
\hline $\begin{array}{l}\text { Babies' average } \\
\text { birth weight }(\mathrm{kg})\end{array}$ & $3.02 \pm 1.52$ & $2.99 \pm 1.61$ & 0.689 \\
\hline Number of abortions & $1.02 \pm 1.24$ & $1.25 \pm 1.68$ & 0.006 \\
\hline Metrorrhagia & $370(57.2)$ & 277 & $<0.0001$ \\
\hline Menorrhagia & 244 & 201 & $<0.0001$ \\
\hline \multicolumn{4}{|l|}{ Loss of trust in others } \\
\hline Yes & $290(56.1)$ & 227 (43.9) & $<0.0001$ \\
\hline No & 1144 & $500(30.4)$ & \\
\hline \multicolumn{4}{|l|}{ Body self-hatred } \\
\hline Yes & 80( & $82(50.6)$ & $<0.0001$ \\
\hline No & $1349(67.7)$ & $644(32.3)$ & \\
\hline \multicolumn{4}{|l|}{ Food addiction } \\
\hline Yes & 102 & 119 & $<0.0001$ \\
\hline No & $1330(68.7)$ & 607 & \\
\hline \multicolumn{4}{|c|}{ Irritable colon or gastric ulcer } \\
\hline Yes & $219(51.2)$ & $209(48.8)$ & $<0.0001$ \\
\hline No & 1202 (59.3) & $517(40.7)$ & \\
\hline \multicolumn{4}{|c|}{ Self-perception as hopeless a person } \\
\hline Yes & 69 (41.2) & $96(58.8)$ & $<0.0001$ \\
\hline No & 1355 (68.2) & $632(31.8)$ & \\
\hline
\end{tabular}

${ }^{*}$ Data are presented as frequency (per cent) unless otherwise specified. 
Table 5 Marital satisfaction scale demonstrating the women's level of satisfaction in their marriages ${ }^{\dagger}$

\begin{tabular}{|c|c|c|c|c|c|c|c|c|}
\hline & \multicolumn{2}{|c|}{ Physically abused ${ }^{\star}$} & \multicolumn{2}{|c|}{ Sexually abused* } & \multicolumn{2}{|c|}{ Emotionally abused* } & \multicolumn{2}{|c|}{ Ever abused* } \\
\hline & No & Yes & No & Yes & No & Yes & $\overline{\text { No }}$ & Yes \\
\hline \multicolumn{9}{|c|}{ Extremely dissatisfied } \\
\hline & $24(1.3)$ & $19(7.1)$ & $34(1.6)$ & $9(8.2)$ & $17(1.1)$ & $26(3.9)$ & $16(1.1)$ & $27(3.7)$ \\
\hline \multicolumn{9}{|c|}{ Very dissatisfied } \\
\hline & $25(1.3)$ & $14(5.2)$ & $32(1.6)$ & $7(6.4)$ & $15(1.0)$ & $24(3.6)$ & $15(1.0)$ & $24(3.3)$ \\
\hline \multicolumn{9}{|c|}{ Somewhat dissatisfied } \\
\hline & $29(1.5)$ & $22(8.2)$ & $40(1.9)$ & $11(10.0)$ & $14(0.9)$ & $37(5.5)$ & $11(0.8)$ & $40(5.4)$ \\
\hline \multicolumn{9}{|c|}{ Mixed } \\
\hline & $236(12.4)$ & $76(28.3)$ & 279 (13.5) & $33(30.0)$ & $180(12)$ & $132(19.6)$ & $170(11.8)$ & $142(19.3)$ \\
\hline \multicolumn{9}{|c|}{ Somewhat satisfied } \\
\hline & $627(33.0)$ & $68(25.3)$ & $676(32.8)$ & $19(17.3)$ & $456(30.5)$ & $239(35.5)$ & $436(30.3)$ & 259 (35.3) \\
\hline \multicolumn{9}{|c|}{ Very satisfied } \\
\hline & $655(34.4)$ & $45(16.7)$ & $681(33.0)$ & $19(17.3)$ & $557(37.2)$ & $143(21.2)$ & $537(37.4)$ & $163(22.2)$ \\
\hline \multicolumn{9}{|c|}{ Extremely satisfied } \\
\hline & $306(16.1)$ & $25(9.3)$ & 319 (15.5) & 12 (10.9) & $258(17.2)$ & $73(10.8)$ & $252(17.5)$ & 79 (10.8) \\
\hline Total & 1902 (82.7) & $269(11.7)$ & 2061 (89.6) & $110(4.8)$ & $1497(65.1)$ & 674 (29.3) & 1437 (62.5) & 734 (31.9) \\
\hline
\end{tabular}

${ }^{*} p \leq 0.0001$.

†Data are presented as frequency (per cent).

Women of lower educational status were significantly more likely to report abuse, which is in line with those of other authors ${ }^{10}$ who reported DV to be more common among women with a lower level of education. In their report, the authors found that women with secondary or higher levels of education were significantly less likely to experience violence than women with less than 5 years of education. In another report, the authors found that a reduction in DV risk was associated with secondary education for the woman and her partner; there was less consistent evidence of a protective effect of primary education. ${ }^{22}$

Women who reported DV were likely to report that their spouses had completed at least primary or secondary education $(\mathrm{p}<0.0001)$; however, we did not find a significant association between spousal income and DV. Previous analyses of community samples have shown that that low socioeconomic status ${ }^{24} 2526$ and low educational status were significant predictors of DV. ${ }^{442627}$ In addition, other studies have found that indicators of household economic prosperity and education of the male partner were inversely associated with the risk of DV. ${ }^{28} 29$

Findings from a community and clinical study indicated that among the demographic factors that were determinants of DV, the more children a woman had, the less likely was she to be beaten by her partner. ${ }^{28} 30$ On the contrary, our analyses showed that abused women were more likely to have more children than their non-abused peers.

Contrary to Caetano et $a l \mathrm{~s}^{31}$ report that partner violence is less likely as men age, we found that the spouses of abused women were significantly older than those of non-abused women. However, it is uncertain whether our finding is affected by the age difference between partners, which could set up an unequal balance of power. Findings from another study indicated that having a partner of the same age or younger was a risk factor for intimate partner violence (after controlling for factors such as acceptance of violence, younger age and age difference between partners). ${ }^{10}$

In our study, women who reported abuse were likely to report that their male partner was a smoker $(\mathrm{p}<0.0001)$; a significantly lower proportion of abused women reported that their male partners were alcohol users $(p=0.001)$. Findings suggest a link between cigarette smoking and alcohol use in perpetrators of DV. In one study, the authors found that daily smokers had significantly more days of alcohol use prior to starting substance abuse treatment compared with non-daily smoking alcohol-dependent offenders of IPV. ${ }^{10}$ Other authors reported that DV was associated with higher rates of drunkenness. ${ }^{32} 33$ A similar association was reported between drug misuse and $\mathrm{DV}^{34}$

Several studies have reported a range of mental and physical health disorders in women victims of DV. ${ }^{35} 3637{ }^{38}$ While other authors ${ }^{37}$ have cited physical disabilities, suicidal thoughts and suicidal attempts to be common among victims of DV, others have reported cases of abruptio placenta, preterm labour and kidney infections in women who were physically abused. ${ }^{35}$ In our study, abused women were more likely to report body self-hatred, food addiction, hopelessness and gynaecological disorders such as metrorrhagia and menorrhagia. Although there is no clear explanation to our findings, we believe that emotional abuse, which was the common form of abuse in our sample, might have led to negative health perceptions. ${ }^{39}$

Our findings demonstrated that abused women were more likely to report dissatisfaction in their marriages. In addition, less than $5 \%$ sought help or planned to seek assistance from social services probably because they are poorly developed in Saudi Arabia. ${ }^{39}{ }^{40}$ It is plausible that women justified violence, ${ }^{41424344}$ which made it difficult 
for them to leave their spouses or report DV. In addition, in Muslim communities some may have wrongly conceived verses from the Qu'ran as religious justification to cite for wife abuse. ${ }^{4146}$ Abuse, on the contrary, is neither condoned nor supported by the Islamic religion. However, this view was not explored, as it was not the focus of our study.

This study is the first to assess risk factors associated with DV among women in a Saudi society. However, our study has some limitations. The cross-sectional nature of our study prohibits conclusions about causality, predictive ability and labelling variables as risk factors. For better assessment of DV, longitudinal cohort studies should be performed to identify past-year exposure to $\mathrm{DV}$ at baseline and receipt of DV-relevant preventive services, including counselling for safety and domestic abuse concerns. There is also a need for further research to evaluate intervention in DV cases. Only women were surveyed, and the data relied solely on the reports of the participants. Moreover, we recruited a convenience sample of women owing to the difficulties in approaching leaders of women's gathering groups, who were hesitant to give their approval because of the relatively sensitive nature of our theme. The potential impact on the self-report of women who needed assistance in completing their questionnaires should also be taken into consideration, as sensitive information was obtained. Hence, it is possible that the prevalence of DV in this study may have been underestimated. Also we did not report factors such as gender, race and ethnicity of the psychologist and health assistant who were present during data collection. These factors would have been important to consider when estimating the reliability and validity of our questionnaire. A further limitation is that some women did not respond to certain questions for fear of disclosing too much personal information. Given that different types of addiction are not as rare as they used to be in Saudi Arabia and drug use is a crime punishable by death, ${ }^{46}$ it is possible that drug abuse may have been under-reported in this study. Similarly, alcohol consumption may have been under-reported since its production, importation and consumption are completely banned by the Saudi government. ${ }^{47}$

Taken together, our findings demonstrate that several factors are associated with DV, but financial dependence significantly increases the risk of abuse when all factors are considered. The multifaceted nature of the factors associated with DV against women in this study highlights the need to design effective DV prevention programmes. This may involve educating the population on changing gender norms and addressing issues of abuse through developing social service programmes.

Funding This research received no specific grant from any funding agency in the public, commercial or not-for-profit sectors.

Competing interests None.

Ethics approval Approval to conduct the study was obtained from the Biomedical Ethics Research Committee of King Abdulaziz University.
Provenance and peer review Not commissioned; externally peer reviewed.

Data sharing statement No additional data are available.

Open Access This is an Open Access article distributed in accordance with the Creative Commons Attribution Non Commercial (CC BY-NC 3.0) license, which permits others to distribute, remix, adapt, build upon this work noncommercially, and license their derivative works on different terms, provided the original work is properly cited and the use is non-commercial. See: http:// creativecommons.org/licenses/by-nc/3.0/

\section{REFERENCES}

1. Report of the Fourth World Conference on Women, Beijing, China, 4-15 September. UN Doc. A/Conf.177/20 (1995). http://www.un.org/ womenwatch/confer/beijing/reports/plateng.htm (accessed 14 Oct 2012).

2. Heise L, Ellsberg M, Gottemoeller M. Ending violence against women. Popul Rep 1999;27:1-43.

3. Heise L, Garcia-Moreno C. Violence by intimate partners. In: Krug EG, Dahlberg LL, Mercy JA, Zwi AB, Lozano R. eds World report on violence and health, vol 1. Geneva: World Health Organization, 2002:87-113.

4. Yount K. Resources, family organization, and domestic violence against married women in Minya, Egypt. J Marital Fam 2005;67:579-96.

5. Douki S, Nacef F, Belhadj A, et al. Violence against women in Arab and Islamic countries. Arch Womens Ment Health 2003;6:165-71.

6. Akmatov MK, Mikolajczyk RT, Labeeb S, et al. Factors associated with wife beating in Egypt: analysis of two surveys (1995 and 2005). BMC Womens Health 2008;8:15.

7. Tashkandi A, Rasheed FP. Wife abuse: a hidden problem. A study among Saudi women attending PHC centres. East Mediterr Health $J$ 2009;15:1242-53.

8. Afifi ZE, Al-Muhaideb NS, Hadish NF, et al. Domestic violence and its impact on married women's health in Eastern Saudi Arabia. Saudi Med J 2011;32:612-20.

9. Guimei M, Fikry FE, Esheiba OM. Patterns of violence against women in three communities in Alexandria, Egypt. MCN Am J Matern Child Nurs 2012;37:331-8.

10. Kouyoumdjian FG, Calzavara LM, Bondy SJ, et al. Risk factors for intimate partner violence in women in the Rakai Community Cohort Study, Uganda, from 2000 to 2009. BMC Public Health 2013;13:566.

11. Al-Tawil NG. Association of violence against women with religion and culture in Erbil Iraq: a cross-sectional study. BMC Public Health 2012;12:800.

12. Vest JR, Catlin TK, Chen JJ, et al. Multistate analysis of factors associated with intimate partner violence. Am J Prev Med 2002;22:156-64.

13. Abeya SG, Afework MF, Yalew AW. Intimate partner violence against women in western Ethiopia: prevalence, patterns, and associated factors. BMC Public Health 2011;11:913.

14. Sinha A, Mallik S, Sanyal D, et al. Domestic violence among ever married women of reproductive age group in a slum area of Kolkata. Indian J Public Health 2012;56:31-6.

15. Selic P, Pesjak K, Kersnik J. The prevalence of exposure to domestic violence and the factors associated with co-occurrence of psychological and physical violence exposure: a sample from primary care patients. BMC Public Health 2011;11:621.

16. Al-Mazrou YY, Farid SM, Khan MU. Changing marriage age and consanguineous marriage in Saudi females. Ann Saudi Med 1995;15:481-5.

17. Swahnberg IM, Wijma B. The NorVold Abuse Questionnaire (NorAQ): validation of new measures of emotional, physical, and sexual abuse, and abuse in the health care system among women. Eur J Public Health 2003;13:361-6.

18. Kotelchuck M. Pregnancy Risk Assessment Monitoring System (PRAMS): possible new roles for a National MCH Data System. Public Health Rep 2006;121:6-10.

19. Crane DR, Middle KC, Bean RA. Establishing criterion scores for the Kansas marital satisfaction. Am J Fam Ther 2000;28:53-60.

20. Nybergh L, Taft C, Krantz G. Psychometric properties of the WHO Violence against women instrument in a female population-based sample in Sweden: a cross-sectional survey. BMJ Open 2013;3: e002053.

21. Federal-Provincial-Territorial Ministers Responsible for Status of Women. Assessing violence against women: a statistical profile. Canada. 2002:2-3. 
22. Abramsky $\mathrm{T}$, Watts $\mathrm{CH}$, Garcia-Moreno $\mathrm{C}$, et al. What factors are associated with recent intimate partner violence? Findings from the WHO multi-country study on women's health and domestic violence. BMC Public Health 2011;11:109.

23. Hindin MJ, Adair LS. Who's at risk? Factors associated with intimate partner violence in the Philippines. Soc Sci Med 2002;55:1385-99.

24. Herzog S. Differential perceptions of the seriousness of male violence against female intimate partners among Jews and Arabs in Israel. J Interpers Violence 2004;19:891-900.

25. Jasinski JL. Pregnancy and domestic violence: a review of the literature. Trauma Violence Abuse 2004;5:47-64. Review.

26. Maziak W, Asfar T. Physical abuse in low-income women in Aleppo, Syria. Health Care Women Int 2003;24:313-26.

27. Sahin HA, Sahin HG. An unaddressed issue: domestic violence and unplanned pregnancies among pregnant women in Turkey. Eur $J$ Contracept Reprod Health Care 2003;8:93-8.

28. Koenig MA, Ahmed S, Hossain MB, et al. Women's status and domestic violence in rural Bangladesh: individual- and community-level effects. Demography 2003;40:269-88.

29. Jeyaseelan L, Sadowski LS, Kumar S, et al. World studies of abuse in the family environment-risk factors for physical intimate partner violence. Inj Control Saf Promot 2004;11:117-24.

30. Anderson $\mathrm{BA}$, Marshak $\mathrm{HH}$, Hebbeler $\mathrm{DL}$. Identifying intimate partner violence at entry to prenatal care: clustering routine clinical information. J Midwifery Women's Health 2002;47:353-9.

31. Caetano R, Vaeth PAC, Ramisetty-Mikler S. Intimate partner violence victim and perpetrator characteristics among couples in the United States. J Fam Violence 2008;23:507-18.

32. Easton CJ, Weinberger AH, McKee SA. Cigarette smoking and intimate partner violence among men referred to substance abuse treatment. Am J Drug Alcohol Abuse 2008;34:39-46.

33. Silva MA, Falbo Neto GH, Figueiroa JN, et al. Violence against women: prevalence and associated factors in patients attending a public healthcare service in the Northeast of Brazil. Cad Saude Publica 2010;26:264-72.

34. Shorey RC, Febres J, Brasfield $\mathrm{H}$, et al. The prevalence of mental health problems in men arrested for domestic violence. $J$ Fam Violence 2012;27:741-8.
35. Rachana C, Suraiya K, Hisham AS, et al. Prevalence and complications of physical violence during pregnancy. Eur J Obstet Gynecol Reprod Biol 2002;103:26-9.

36. Ellsberg $\mathrm{M}$, Heise $\mathrm{L}$, Watts $\mathrm{CH}$, et al. Researching violence against women a practical guide for researchers and activists. Washington DC: World Health Organization, 2005.

37. Ellsberg M, Jansen HA, Heise L. Intimate partner violence and women's physical and mental health in the WHO multi-country study on women's health and domestic violence: an observational study. Lancet 2008;371:1165-72.

38. Mohammadi G, Amiraliakbari S, Ramezankhani A. Poor reproductive health among a group of socially damaged Middle Eastern women: a cross-sectional study. Int $J$ Womens Health 2011;3:399-403.

39. Straight E, Harper F, Arias I. The impact of partner psychological abuse on health behaviors and health status in college women. $J$ Interperl Violence 2003;18:1034-54.

40. Douki S, Nacef F, Belhadj A, et al. Violence against women in Arab and Islamic countries. Arch Women's Ment Health 2003;6:165-71.

41. Alzahrani A. Women's sexual health in Saudi Arabia: a focused ethnographic study [dissertation]. Yorkshire: University of Sheffield, 2011.

42. Amowitz LL, Kim G, Reis $\mathrm{C}$. Human rights abuses and concerns about women's health and human rights in southern Iraq. JAMA 2004;291:1471-9.

43. Boy A. What we know about intimate partner violence in the Middle East and North Africa. Violence Against Women 2008;14:53-70.

44. Btoush R, Haj-Yahia MM. Attitudes of Jordanian society toward wife abuse. J Interpers Violence 2008;23:1531-54.

45. Ammar $\mathrm{NH}$. Wife battery in Islam: a comprehensive understanding of interpretations. Violence Against Women 2007;13:516-26.

46. AbuMadini MS, Rahim SI, Al-Zahrani MA, et al. Two decades of treatment seeking for substance use disorders in Saudi Arabia: trends and patterns in a rehabilitation facility in Dammam. Drug Alcohol Depend 2008;97:231-6.

47. Councils Resolutions: Second Term Fourth Year. Al Shoura Council Web site. http://www.shura.gov.sa/wps/wcm/connect/ShuraEn/ internet/Councils+Resolutions/Second+Term/Fourth+Year/ (accessed 14 Oct 2012). 